\title{
Observational Study Comparing Efficacy and Safety Between Preoperative Neoadjuvant Concurrent Chemoradiotherapy and Chemotherapy for Patients with Unresectable Locally Advanced or Metastatic Gastric Cancer
}

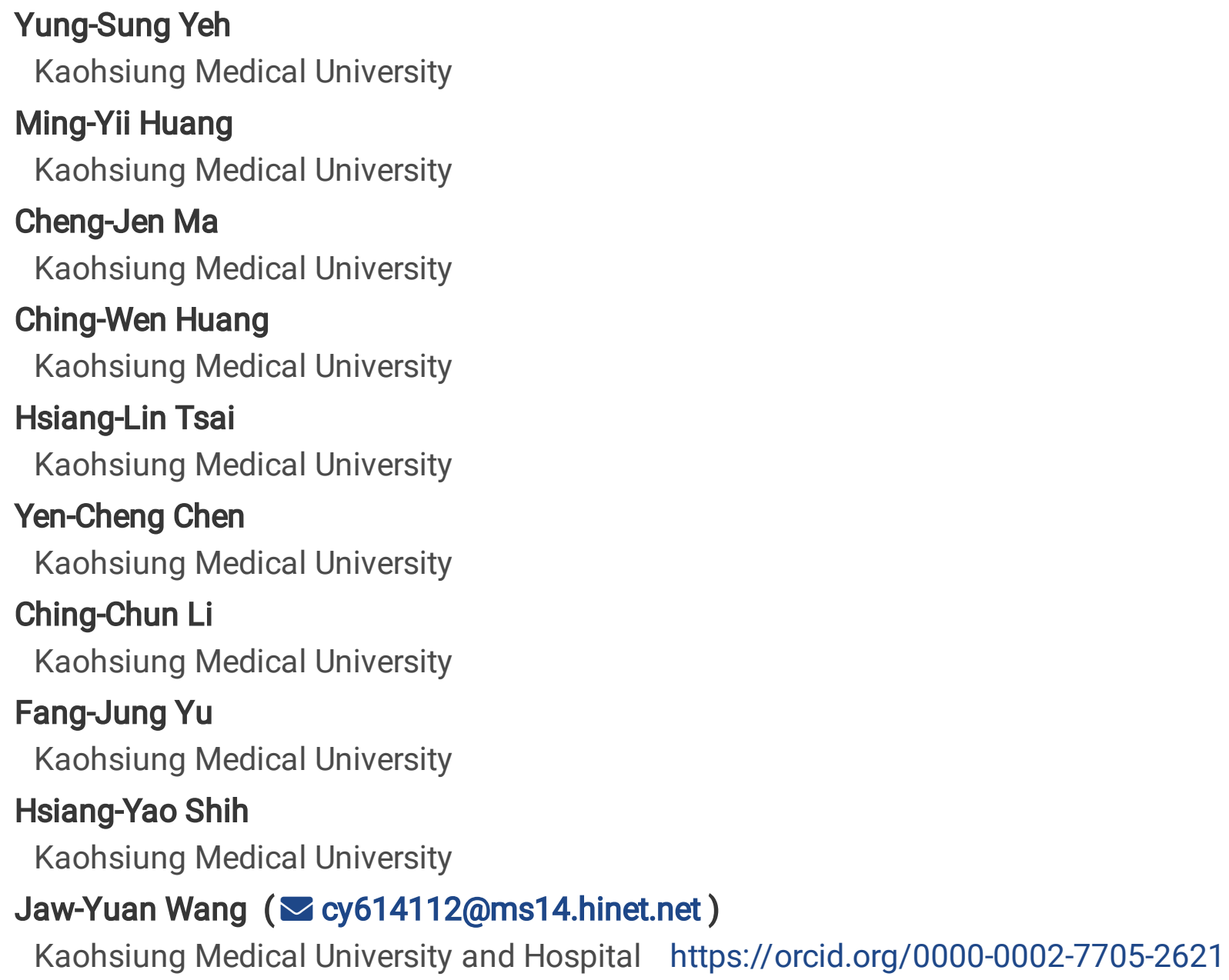

Research article

Keywords: locally advanced gastric cancer, metastatic gastric cancer, neoadjuvant concurrent chemoradiotherapy, neoadjuvant chemotherapy

Posted Date: December 16th, 2019

DOI: https://doi.org/10.21203/rs.2.18868/v1 
License: (c) (i) This work is licensed under a Creative Commons Attribution 4.0 International License. Read Full License

Version of Record: A version of this preprint was published at Journal of Oncology on September 7th, 2020. See the published version at https://doi.org/10.1155/2020/6931317. 


\section{Abstract}

Background: Dismal outcomes in patients with locally advanced or metastatic gastric cancer (GC) highlights the need for effective systemic neoadjuvant treatment strategies to improve clinical results. Neoadjuvant multimodality strategies vary widely. This study compared the efficacy, safety, and clinical outcomes of preoperative neoadjuvant CCRT and chemotherapy for such patients.

Methods: Sixty-five patients with histologically confirmed locally advanced or metastatic GC following neoadjuvant CCRT or computed tomography (CT) were retrospectively enrolled between January 2010 and April 2019. Clinical outcomes included response, progression-free survival (PFS), and overall survival (OS), and toxicity was compared between the two groups.

Results: Of the 65 patients, 18 (27.7\%) were in the response group (2 patients with complete response and 16 with partial response) and 47 (72.3\%) in the nonresponse group (29 patients with stable disease and 18 with progressive disease). Multivariate analysis revealed no independent response predictor between CCRT and CT groups (all $P>0.05$ ). Furthermore, results revealed no statistical differences in toxicity between the two groups (all $P>0.05$ ). With a follow-up median of 12 months (ranging 6-48 months), 12 -month OS and PFS were $39.7 \%$ and $20.4 \%$ in the CCRT group and $30.3 \%$ and $13.2 \%$ in the chemotherapy group, respectively. The median OS and PFS were 14.0 months (95\% $\mathrm{Cl} 9.661-18.339)$ and 9.0 months $(95 \% \mathrm{Cl} 6.805-11.195)$ in the CCRT group and 10.0 months (95\% $\mathrm{Cl} 6.523-13.477)$ and 8.0 months $(95 \% \mathrm{Cl} 6.927-9.073)$ in the CT group, respectively. Both OS $(P=0.011)$ and PFS $(P=0.008)$ in patients with CCRT were significantly better than those in patients with chemotherapy alone.

Conclusions: Neoadjuvant CCRT achieved more favorable OS and PFS than did neoadjuvant chemotherapy alone, without significant increases of toxicity in patients. However, prospective randomized trials comparing treatment modalities are necessary to confirm potential advantages of preoperative neoadjuvant CCRT.

\section{Background}

Gastric cancer (GC) is one of the most common malignancies and, despite a steady decline, GC remains the leading cause of death with widely varying incidence worldwide [1]. Despite earlier detection of GC and considerable advancements in treatments that improve opportunities for survival, its mortality and morbidity rates remain high, with local advanced or distant metastases occurring in up to $60 \%$ of patients $[2,3]$. In patients with unresectable locally advanced or metastatic GC, the median survival time without chemotherapy is approximately 3-4 months. Complete surgical resection remains the only chance for cure, and multimodality treatment approaches are implemented to improve survival chances [1]. Thus, dismal outcomes in patients with locally advanced or metastatic GC highlights the need for effective systemic neoadjuvant treatment to improve clinical results.

Recently, several clinical trials have shown that neoadjuvant CCRT can benefit patient survival after surgery for GC $[4,5]$. Moreover, preoperative neoadjuvant CCRT has more theoretical benefits than 
neoadjuvant chemotherapy in patients with unresectable locally advanced or metastatic GC, including more favorable progression-free survival (PFS) and overall survival (OS) without a significant toxicity increase in patients [6]. These strategies improve disease-related outcomes more than surgery alone but are associated with higher rates of treatment-related morbidity. Illustrating this fact, only $64 \%$ of patients in the Intergroup-0116 trial and 42\% in the Medical Research Council Adjuvant Gastric Infusional Chemotherapy trial could complete their prescribed treatment courses [7, 8]. Hence, establishment of a more precise treatment protocol that appropriately selects patients and provides specific therapy is ongoing.

Patients with more locally advanced GC who underwent gastrectomy after preoperative CCRT experienced outcomes that varied between favorable and poor. In this study, we presented our experience with preoperative neoadjuvant CCRT versus chemotherapy alone in patients with unresectable locally advanced or metastatic GC and compared baseline characteristics, efficacy, and safety between the two groups.

\section{Methods}

\section{Data Source and Study Design}

This study was conducted at Kaohsiung Medical University Hospital with approval from the hospital's institutional review board (KMUHIRB-20130022) and informed consent was obtained from all patients. The study started in January 2010 and as of April 2019, 65 patients with histologically confirmed locally advanced T4 or metastatic GC have been included. Baseline investigations consist of blood tests, gastroendoscopy with tumour biopsy samples, complete history review and physical examination, and image studies (i.e., chest radiography, abdominal computed tomography [CT], and additional magnetic resonance imaging $[\mathrm{MRI}]$ if the CT scan could not clarify the cancer stage). TNM classification was determined according to the American Joint Commission on Cancer/Union for International Cancer Control criteria [9].

\section{Patient Selection}

Patients with histologically proven locally advanced T4 or metastatic GC are eligible for this study. Patients should be at least 18 years old with an Eastern Cooperative Oncology Group performance status of $0-2$. Patients must have adequate hematological, renal and liver function. Exclusion criteria include: central nervous system metastases or previous malignancy, active infections or serious concurrent medical illness (i.e., clinical significant cardiac disease or liver disease, known peripheral neuropathy), life expectancy $<3$ months, prior radiotherapy or chemotherapy, and inability to receive neoadjuvant therapy.

\section{Clinicopathological Characteristics}

Clinicopathological characteristics, such as age, sex, tumor size, tumor invasion depth, lymph node metastasis, clinical TNM status, vascular invasion, perineural invasion, tumor location, histological tumor 
differentiation grade, pretreatment metastasis site, and pretreatment serum carcinoembryonic antigen (CEA) level were analyzed. This study aimed to explore the efficacy and safety profile of preoperative CCRT in locally advanced or metastatic GC versus preoperative chemotherapy.

\section{Treatment Modalities}

Currently, no particular neoadjuvant protocol is internationally regarded as superior in the multimodal therapeutic armamentarium. Interpretation of trial results is controversial, which results in strong interinstitutional differences concerning radiotherapy and chemotherapy sequence for the treatment of patients with locally advanced T4 or metastatic GC. Whether preoperative chemotherapy or CCRT should be recommended for the treatment of patients with locally advanced T4 or metastatic GC remains uncertain. Furthermore, both options are suggested by guidelines supported by the National Comprehensive Cancer Network. In this study, we compared the survival data of patients with locally advanced T4 or metastatic GC, treated either with CCRT or chemotherapy, based on real world data from one institution, and we additionally reviewed the current literature.

\section{Chemotherapy}

The 65 patients were treated with an mFOLFOX-4-based regimen that comprised the following: On day 1, oxaliplatin $\left(85 \mathrm{mg} / \mathrm{m}^{2}\right)$ and leucovorin $\left(200 \mathrm{mg} / \mathrm{m}^{2}\right)$ were administered over a 2-h period, followed by a 48-h continuous infusion of 5-FU at a dose of $2400 \mathrm{mg} / \mathrm{m}^{2}$ every 2 weeks. The primary endpoints of this study were response rate, PFS, and OS. The secondary endpoints were acute toxicities during preoperative CCRT or chemotherapy

\section{Radiotherapy}

Three-dimensional conventional radiotherapy (3D-CRT) was delivered using a $2100 \mathrm{C} / \mathrm{D}$ linear accelerator (Varian Medical Systems, Palo Alto, CA, USA). For the 3D-CRT plan, we used anterior-posterior and posterior-anterior fields with photon energy at $10 \mathrm{MV}$. The dose specification for 3D-CRT encompassed the planning target volume (PTV) in all directions within the $95 \%$ isodose line. Volumes receiving more than $110 \%$ of the dose prescribed to the PTV were minimized. Reference points were selected either in the central part of PTV or at the intersection of beam axes from the International Commission on Radiation Units and Measurements (ICRU; Reports 50 and 62). The radiation portal fields were designed as follows: (i) proximal one-third/ cardia/esophagogastric junction primaries included $3-5 \mathrm{~cm}$ of distal esophagus, medial left hemidiaphragm, adjacent pancreatic body, and nodal areas at risk including adjacent paraesophageal, perigastric, suprapancreatic, and celiac lymph nodes; (ii) middle one-third/body primaries included pancreatic body should and nodal areas at risk including perigastric, suprapancreatic, celiac, splenic hilar, porta hepatic, and pancreaticoduedenal lymph nodes; and (iii) distal onethird/antrum/pylorus primaries included pancreatic head, 3-5 cm margin duodenal stump margin if gross lesions extended to the gastroduodenal junction, and nodal areas at risk including perigastric, suprapancreatic, celiac, splenic hilar, porta hepatic, and pancreaticoduedenal lymph nodes. Radiotherapy consisted of 45-50.4 Gy in 25-28 fractions over 5 weeks. 
Image-guided (IG) intensity-modulated radiotherapy (IMRT) plans were generated either with a Hi-Art helical tomotherapy unit, version 2.2.4.1 (TomoTherapy, Inc., Madison, WI, USA), or Eclipse, version 8.6 (Varian Medical Systems). The tomotherapy unit combined rotational IMRT with translational movement from the couch. A fixed-jaw mode with a field width of 2.5 or $5 \mathrm{~cm}$ was used for treatment planning. The pitch varied from 0.215 to 0.287 . The modulation factor ranged from 2 to 3 depending on homogeneity and conformity. The gross tumor volume encompassed gastric tumors and clustered lymph nodes or lymph nodes with diameters greater than $1 \mathrm{~cm}$. The clinical target volume (CTV) included the primary tumor, and adjacent lymphatic drainage depended on primary tumor location. Superior, inferior, and radial margins of 5-7 mm outside the CTV were added to form the PTV.

In the IG-IMRT group, the tumor and boost beams were combined into one integrated treatment plan; thus, these patients were treated with the same plan for each fraction throughout the entire course of radiotherapy. Fractionation schemes comprised 25 daily fractions of $1.8 \mathrm{~Gy}$ to the pelvis and $2 \mathrm{~Gy}$ to the gastric tumor and involved nodes. Optimization reduced doses for the bowel, kidney, liver, and spinal cord. These constraints were also applied to IMRT treatment plans on Varian and comprised beams with multileaf collimator shielding conforming to the PTV. The goal was to encompass the PTV in all directions within the $95 \%$ isodose line. Volumes receiving more than $110 \%$ of the dose prescribed to the PTV were minimized. Volumetric arc therapy was used when suitable. IMRT plans were reviewed using ICRU 83 recommendations. Before each RT fraction, patients were repositioned according to image guidance through megavoltage or cone beam CT, which was coregistered with a planning kilovoltage CT. A dose of 50 Gy was administered to the PTV50 (tumor and enlarged nodes) and 45 Gy to the PTV45 (adjacent high risk nodal area) through a simultaneous integrated boost scheme in the IG-IMRT group. All dose schedules were administered 5 days per week.

\section{Toxicity}

Safety and toxicity were evaluated in each cycle by using the National Cancer Institute Common Terminology Criteria for Adverse Events (CTCAE), version 4.03 (https://ctep.cancer.gov/protocoldevelopment/electronic_applications/ctc.htm, accessed in 2018). Peripheral neuropathy was graded according to the following oxaliplatin-specific scale: grade 1 , paresthesia or dysesthesia of a short duration with complete recovery before the next cycle; grade 2 , paresthesia persisting between two cycles without functional impairment; and grade 3, permanent paresthesia interfering with function [2,3]. Neoadjuvant chemotherapy was discontinued in cases of unacceptable toxicity (>grade 3), disease progression, or patient refusal to continue treatment $[2,3]$.

\section{Evaluation of Response and Efficacy Assessment}

Physical examination, liver and kidney function tests, complete blood count and serum CEA level examination, and electrocardiogram were performed before and after every two weeks of treatment. Abdominal CT and additional MRI are performed every 3 months during chemotherapy, if necessary, chest X-ray is performed annually. A bone scan or positron emission tomography scan is selectively performed to display images of suspicious findings at specific locations of CT or MRI and suspicious 
metastases. All enrolled patients were followed up every 3 months until the last visit or death. The median follow-up time for all patients was 12 months (range, 6-48 months).

Patient responses were classified according to the Response Evaluation Criteria in Solid Tumors [2, 3]. Complete remission (CR) is the disappearance of treatment for all target cancer lesions. Partial response (PR) is a reduction of at least $30 \%$ of the sum of the longest diameters of metastatic lesions, with no signs of new lesions. Progressive disease (PD) is a cumulative increase in the longest diameter of the target lesion by at least $20 \%$, and the smallest sum of the longest diameters recorded before the patient begins treatment is used as a reference. The PD can also recognize one or more new lesions. The contraction rate of stable disease (SD) is not sufficient to meet the PR criteria, and the increase is not sufficient to meet the PD criteria [2]. Finally, PFS was determined by measuring the time interval between the start of neoadjuvant CCRT or chemotherapy and the first record of progression, regardless of the patient's treatment status or final follow-up, while OS was measured by neoadjuvant CCRT or chemotherapy to chemotherapy. The starting time interval is determined. Date of death or last follow-up $[2,3]$.

\section{Statistical Analysis}

Continuous variables are presented as the mean $\pm S D$, and dichotomous variables are presented as numbers and percentage values. All data were analyzed using SPSS (version 20.0, SPSS Inc., Chicago, IL, USA). The chi-square test was used to compare toxicity and outcomes. Univariate analyses and a mutltivariate Cox proportional hazard regression were performed to evaluate independent predictors. PFS and OS were calculated and plotted according to Kaplan-Meier methods, and the log-rank test was used to compare time-to-event distribution. A $P$ value of less than 0.05 was considered statistically significant.

\section{Results}

\section{Patient Demographics}

From January 2010 to April 2019, 65 patients with locally advanced or metastatic GC who received firstline neoadjuvant preoperative CCRT and chemotherapy were enrolled. Their characteristics are listed in Table 1. All 65 patients received at least six chemotherapy cycles with or without preoperative radiotherapy and were eligible for efficacy and toxicity analysis. The patients included 42 men and 22 women who had a mean age of 65.4 years (ranging $31-85$ years). Upon baseline gastroesophagoscopy and abdominal CT, 47 patients $(72.3 \%)$ were observed to have T4 tumors, 24 patients exhibited distant metastasis (36.9\%), and all patients had $\mathrm{N}+$ disease.

Following neoadjuvant CCRT or chemotherapy, 25 (38.5\%) of the 65 patients underwent resection with curative intent. According to the pathological reports of these 25 patients, positive vascular invasion and perineural invasion were observed in $10(15.4 \%)$ and 11 (16.9\%), respectively. Histologically, no tumors were well-differentiated; instead, 6 tumors (9.2\%) were moderately differentiated, and 19 tumors (29.2\%) were poorly differentiated. 
The most common location of primary tumors was the antrum (47.7\%), followed by cardia $(27.7 \%)$, body (27.7\%), diffuse (27.7\%), and gastric stump (4.6\%). Additionally, the peritoneum (12.3\%), liver (10.8\%), lungs (9.2\%), and ovaries (4.6\%) were the most common sites of distant metastases. Among all 65 patients, 17 (26.2\%) exhibited T down-staging, 16 (24.6\%) had N down-staging, and 18 (27.7\%) had TNM down-staging after neoadjuvant therapy.

\section{Toxicity}

Surgeons and radiation oncologists recorded acute toxicities according to the CTCAE, version 4.03 (https://ctep.cancer.gov/protocoldevelopment/electronic_applications/ctc.htm, accessed in July 2019). The most frequent grade 3/4 hematological and nonhematological toxicities are presented in Table 2 . Major grade 3/4 hematological toxicities included neutropenia, febrile neutropenia, and thrombocytopenia, which appeared in four (6.2\%), three (4.6\%), and one (1.5\%) patient, respectively. Other nonhematological toxicities reaching grade $3 / 4$ status were nausea/vomiting (15.4\%), anorexia/fatigue (13.8\%), abnormal liver function (7.7\%), abnormal renal function (7.7\%), peripheral neuropathy (6.2\%), stomatitis $(6.2 \%)$, diarrhea (6.2\%), and constipation (4.6\%). All treatment-related toxicities were treated with proper medical care, and no treatment-related deaths occurred. No additional safety concerns were identified in the current study. These results revealed no statistical difference of toxicities between the two groups (all $P>0.05$ ).

\section{Clinicopathological Correlation}

Preoperative neoadjuvant CCRT was performed in 30 patients (46.2\%) and chemotherapy in 35 patients (53.8\%). No significant association was observed between these two preoperative neoadjuvant treatment modalities and baseline clinicopathological features, namely age, sex, tumor size, clinical T status, clinical N status, vascular invasion, perineural invasion, clinical TNM stage, pretreatment serum CEA level, and posttreatment serum CEA level (Table 3 , all $P>0.05$ ).

\section{Efficacy}

All patients were evaluated for tumor response. Major responses were observed in 18 patients $(27.7 \%)$, of which 2 patients (3.1\%) underwent CR and 16 patients (24.6\%) underwent PR. In addition, 29 patients (44.6\%) exhibited SD, and 18 patients $(27.7 \%)$ had PD. Disease control rates were observed in 48 patients (73.9\%) in the CCRT group and 25 patients (83.3\%) in the chemotherapy group.

\section{Correlation between Response and Clinicopathological Features}

Among the 65 patients, 18 (27.7\%) were categorized into the response group (2 CR and 14 PR) and 47 (72.3\%) into the nonresponse group (29 SD and 18 PD). From univariate analysis of the correlation between the response group and clinicopathological features, we observed no significant differences between preoperative CCRT and chemotherapy (Table 4). No significant differences in age, sex, tumor size, clinical T status, clinical N status, vascular invasion, perineural invasion, clinical TNM stage, pretreatment serum CEA level, and post-treatment serum CEA level were observed (all $P>0.05$ ). In 
addition, the multivariate logistic regression analysis revealed no independent predictor of response between CCRT and chemotherapy groups (all $P>0.05$ ).

\section{PFS and OS Based on Preoperative Neoadjuvant CCRT or Chemotherapy}

PFS and OS based on preoperative neoadjuvant CCRT or chemotherapy are displayed in Figure 1. Median OS and PFS were 14.0 months (95\% Cl: 9.661-18.339) and 9.0 months (95\% Cl: 6.805-11.195), respectively, in CCRT group patients. By contrast, median OS and PFS were 10.0 months (95\% Cl: 6.52313.477) and 8.0 months (95\% Cl: 6.927-9.073), respectively, in chemotherapy group patients. The 12month OS rates in patients with CCRT or chemotherapy were $39.7 \%$ and $30.3 \%$, respectively, whereas the 12-month PFS rates in patients with CCRT or chemoradiotherapy were $20.4 \%$ and $13.2 \%$, respectively.

Notably, both OS and PFS in patients with CCRT were better than those in patients with chemotherapy ( $P$ $=0.011$ and $P=0.008$, respectively). CCRT, rather than chemotherapy, appeared effective for achieving better survival benefit.

\section{Discussion}

GC remains a leading malignancy worldwide, and management of patients with locally advanced or metastatic GC has not substantially changed in the last few decades. A neoadjuvant strategy may increase the likelihood of completing multimodality therapy, particularly when surgical management is associated with significant morbidity and complications that may preclude timely adjuvant therapy [914].

Preoperative concurrent chemoradiotherapy (CCRT) is a well-established primary treatment modality in other gastrointestinal malignancies including esophageal $[9,10]$ and rectal cancer $[11,12]$. This treatment approach involves sterilizing the surgical field, potentially reducing the risk of local tumor dissemination at resection. Preoperative CCRT may also allow smaller and more accurate radiation treatment fields, which could improve treatment tolerance and chemotherapy effects [13].

Application of neoadjuvant radiotherapy for patients with unresectable locally advanced or metastatic GC has several additional and distinct advantages. The presence of intact tumors and preserved normal anatomy facilitates treatment planning and may limit toxicity to adjacent organs. By contrast, adjuvant radiotherapy mandates high doses and large treatment fields that may increase toxicity.

In recent years, a multidisciplinary treatment approach including preoperative chemotherapy, radiotherapy, and target therapy has emerged for advanced or metastatic GC, resulting in increased curability and improved survival ${ }^{14}$. Recent studies have suggested that neoadjuvant chemotherapy in patients with locally advanced or metastatic GC can enable curative resection and improve survival [14, 15]. In our previous study, we observed that survival and quality of life of patients with locally advanced or metastatic GC who received neoadjuvant chemotherapy were superior to those of patients who received only supportive care $[2,3]$. 
Low resectability is largely responsible for the poor prognosis of patients with unresectable locally advanced or metastatic GC. Patients who underwent curative surgery experienced better outcomes than did those who did not undergo surgery $[2,16]$. However, radical surgery in patients with locally advanced or metastatic GC is limited because of the high risk of perioperative and postoperative morbidity and mortality and the low rate of resection [17]. Timely implementation of the radical resection of cancer is a key step toward favorable therapeutic results. Therefore, improving survival rates to increase resection rates for treatment of advanced GC is necessary.

A neoadjuvant approach can be applied broadly; however, its advantages may be most pronounced in these specific patient sunsets. In previous prospective studies, patients treated with neoadjuvant CCRT have exhibited higher response rates than did those with chemoradiotherapy alone. Numerous clinical trials have shown that preoperative neoadjuvant CCRT is feasible, and resection rates are higher in patients treated with CCRT $[18,19]$. Many findings are expected from trials that explore ways of improving preoperative treatment strategies for locally advanced or metastatic GC [20-24].

Another main reason for the addition of radiotherapy to preoperative chemotherapy is to achieve better local control. Radiotherapy may reduce focal inflammatory edema and fibrous adhesion of the tumor after chemotherapy. A previous phase $\triangle$ clinical trial reported that neoadjuvant CCRT significantly reduced locoregional recurrence from $34-14 \%$, with only $1 \%$ in-field recurrence $[19,20]$. In a Japanese pilot study, no local recurrence was observed after neoadjuvant CCRT [21].

The present study demonstrated favorable OS and PFS responses for patients with locally advanced or metastatic GC treated with CCRT. In our study, 18 (27.7\%) of the 65 patients were categorized into the response group and the remaining 47 patients $(72.3 \%)$ into the nonresponse group. The results of this study indicated that patients who had locally advanced or metastatic GC with treatment of neoadjuvant CCRT tended to have better PFS and OS than did patients with neoadjuvant chemotherapy alone. We did not observe any difference in the morbidity rate between the two treatments with tolerable toxicity and safety.

Our study has several limitations. This was a small retrospective study, and the long-term survival of patients included in this study is unknown. Despite this limitation, neoadjuvant CCRT prompted a favorable response to survival. Therefore, these results supported the use of neoadjuvant CCRT in the treatment of patients with locally advanced or metastatic GC. However, additional studies conducted with larger sample sizes and careful patient monitoring are required to confirm these findings. More specially designed studies and reliable biological indicators of real functional status are needed to properly select patients for multimodal treatment. The results of such studies could be used to significantly demonstrate therapeutic efficacy in the treatment of patients with locally advanced or metastatic GC.

\section{Conclusion}

Neoadjuvant CCRT achieved a more favorable OS and PFS than did neoadjuvant chemotherapy alone, without significant increases of toxicity in patients with locally advanced or metastatic GC. A prospective 
randomized trial comparing both treatment modalities was conducted to demonstrate the efficacy of preoperative neoadjuvant CCRT.

\section{Abbreviations}

3D-CRT Three-dimensional conventional radiotherapy

5-FU 5-fluorouracil

AJCC American Joint Committee on Cancer

CCRT concurrent chemoradiotherapy

CEA carcinoembryonic antigen

CR complete response

CT computed tomography scan

CTV clinical target volume

FOLFOX chemotherapy of 5-fluorouracil/leucovorin/oxaliplatin

GC gastric cancer

ICRU International Commission on Radiation Units and Measurements

IG image-guided

IMRT intensity-modulated radiotherapy

MRI Magnetic resonance image

NCI CTCAE National Cancer Institute Common Terminology Criteria

OS overall survival

PD progressive disease

PFS progression-free survival

PR partial response

PTV planning target volume

SD Stable disease 


\section{Declarations}

Acknowledgments

Not applicable.

\section{Authors' contributions}

Conception, design data analysis and interpretation: YSY, MYM, CJM, JYW. Collection and interpretation of pathological data: CWH, HLT, YCC. Collection and assembly of patient data: CCL, FJY, HYS. Manuscript writing and final approval of manuscript: all authors.

\section{Funding}

This work was supported by grants from the Ministry of Science and Technology (MOST108-2321-B-037001, MOST107-2321-B-037-003, MOST107-2314-B-037-116, MOST107-2314-B-037-022-MY2, MOST1072314-B-037-023-MY2), the Ministry of Health and Welfare (MOHW107-TDU-B-212-123006, MOHW107TDU-B-212-114026B, MOHW108-TDU-B-212-133006, MOHW108-TDU-B-212-124026) funded by health and welfare surcharging of tobacco products, Kaohsiung Medical University Hospital (KMUH107-7R28, KMUH107-7R29, KMUH107-7R30, KMUH107-7M22, KMUH107-7M23, KMUHS10701, KMUHS10801, KMUHS10804, KMUHS10807), and Center for Cancer Research, Kaohsiung Medical University (KMUTC108A04). In addition, this study was supported by grants from the Taiwan Precision Medicine Initiative and Biomarker Discovery in Major Diseases of Taiwan Project (AS-BD-108-1), Academia Sinica, Taiwan, R.O.C.

\section{Availability of data and materials}

The datasets supporting the conclusions of this manuscript are included within the article. Please contact author for raw data requests.

\section{Ethics approval and consent to participate}

The present study was approved by the Institutional Review Board of Kaohsiung Medical University Hospital (KMUHIRB-20130022) and conducted in accordance with provision of the Declaration of Helsinki. Informed consent to participate in the study had been obtained from participants by writing. Patients' clinical outcomes and survival statuses were regularly followed up.

\section{Consent for publication}

Not applicable.

\section{Competing interests}

The authors declare that they have no competing interests. 


\section{References}

1. Charalampakis N, Economopoulou P, Kotsantis I, Tolia M, Schizas D, Liakakos T, et al. Medical management of gastric cancer: a 2017 update. Cancer Med. 2018;7:123-33.

2. Yeh YS, Chen YT, Tsai HL, Huang CW, Ma CJ, Su WC, et al. Predictive Value of ERCC1, ERCC2, and XRCC Expression for Patients with Locally Advanced or Metastatic Gastric Cancer Treated with Neoadjuvant mFOLFOX-4 Chemotherapy. Pathol Oncol Res. 2019

3. Yeh YS, Tsai HL, Ma CJ, Wu DC, Lu CY, Wu IC, et al. A retrospective study of the safety and efficacy of a first-line treatment with modified FOLFOX-4 in unresectable advanced or recurrent gastric cancer patients. Chemotherapy. 2012;58:411-8.

4. Macdonald JS, Smalley SR, Benedetti J, HundahI SA, Estes NC, Stemmermann GN, et al. Chemoradiotherapy after surgery compared with surgery alone for adenocarcinoma of the stomach or gastroesophageal junction. N Engl J Med. 2001;345:725-30.

5. Kim TH, Park SR, Ryu KW, Kim YW, Bae JM, Lee JH, et al. Phase 3 trial of postoperative chemotherapy alone versus chemoradiation therapy in stage III-IV gastric cancer treated with R0 gastrectomy and D2 lymph node dissection. Int J Radiat Oncol Biol Phys. 2012;84:e585-92.

6. Chang JS, Choi Y, Shin J, Kim KH, Keum KC, Kim HS, et al. Patterns of Care for Radiotherapy in the Neoadjuvant and Adjuvant Treatment of Gastric Cancer: A Twelve-Year Nationwide Cohort Study in Korea. Cancer Res Treat. 2018;50:118-28.

7. Zhang ZX, Gu XZ, Yin WB, Huang GJ, Zhang DW, Zhang RG. Randomized clinical trial on the combination of preoperative irradiation and surgery in the treatment of adenocarcinoma of gastric cardia (AGC)-report on 370 patients. Int J Radiat Oncol Biol Phys. 1998;42:929-34.

8. Cunningham D, Allum WH, Stenning SP, Thompson JN, Van de Velde CJ, Nicolson M, et al. Perioperative chemotherapy versus surgery alone for resectable gastroesophageal cancer. $\mathrm{N}$ Engl J Med. 2006;355:11-20.

9. Amin MB, GreeneFL, Edge SB, Compton CC, Gershenwald JE, Brookland RK, et al. The Eighth Edition AJCC Cancer Staging Manual: Continuing to build a bridge from a population-based to a more "personalized" approach to cancer staging.CA Cancer J Clin. 2017;67:93-99.

10. van Hagen P, Hulshof MC, van Lanschot JJ, Steyerberg EW, van Berge Henegouwen MI, Wijnhoven $\mathrm{BP}$, et al. Preoperative chemoradiotherapy for esophageal or junctional cancer. N Engl J Med. 2012;366:2074-84.

11. Sauer R, Becker H, Hohenberger W, Rödel C, Wittekind C, Fietkau R, Martus P, et al. Preoperative versus postoperative chemoradiotherapy for rectal cancer. N Engl J Med. 2004;351:1731-40.

12. Huang MY, Lee HH, Tsai HL, Huang CW, Yeh YS, Ma CJ, et al. Comparison of efficacy and safety of preoperative Chemoradiotherapy in locally advanced upper and middle/lower rectal cancer. Radiat Oncol. 2018;13:53.

13. Pepek JM, Chino JP, Willett CG, Palta M, Blazer lii DG, Tyler DS, et al. Preoperative chemoradiotherapy for locally advanced gastric cancer. Radiat Oncol. 2013;8:6. 
14. An JY, KimHI, Cheong JH, Hyung WJ, Kim CB, Noh SH. Pathologic and oncologic outcomes in locally advanced gastric cancer with neoadjuvant chemotherapy or chemoradiotherapy. Yonsei Med J. 2013;54:888-94.

15. Sym SJ, Chang HM, Ryu MH, Lee JL, Kim TW, Yook JH,et al. Neoadjuvant docetaxel, capecitabine and cisplatin (DXP) in patients with unresectable locally advanced or metastatic gastric cancer. Ann Surg Oncol. 2010;17:1024-32.

16. Hu JB, Sun XN, Gu BX, Wang Q, Hu WX. Effect of intensity modulated radiotherapy combined with s1-based chemotherapy in locally advanced gastric cancer patients. Oncol Res Treat. 2014;37:11-6.

17. Cheng CT, Tsai CY, Hsu JT, Vinayak R, Liu KH, Yeh CN, et al. Aggressive surgical approach for patients with T4 gastric carcinoma: promise or myth? Ann Surg Oncol. 2011;18:1606-14.

18. Stahl M, Walz MK, Stuschke M, Lehmann N, Meyer HJ, Riera-Knorrenschild J, et al. Phase III comparison of preoperative chemotherapy compared with chemoradiotherapy in patients with locally advanced adenocarcinoma of the esophagogastric junction. J Clin Oncol. 2009;27:851-6.

19. Oppedijk V, van der Gaast A, van Lanschot JJ, van Hagen P, van Os R, van Rij CM, et al. Patterns of recurrence after surgery alone versus preoperative chemoradiotherapy and surgery in the CROSS trials. J Clin Oncol. 2014;32:385-91.

20. Okines AF, LangleyRE, Thompson LC, Stenning SP, Stevenson L, Falk S, et al. Bevacizumab with perioperative epirubicin, cisplatin and capecitabine (ECX) in localised gastro-oesophageal adenocarcinoma: a safety report. Ann Oncol. 2013;24:702-9.

21. Inoue T, Yachida S, Usuki H, Kimura T, Hagiike M, Okano K, et al. Pilot feasibility study of neoadjuvant chemoradiotherapy with S-1 in patients with locally advanced gastric cancer featuring adjacent tissue invasion or JGCA bulky N2 lymph node metastases. Ann Surg Oncol. 2012;19:2937-45.

22. Bang YJ, Van CutsemE, Feyereislova A, Chung HC, Shen L, Sawaki A, et al. Trastuzumab in combination with chemotherapy versus chemotherapy alone for treatment of HER2-positive advanced gastric or gastro-oesophageal junction cancer (ToGA): a phase 3, open-label, randomised controlled trial. Lancet. 2010;376:687-97.

23. Dikken JL, van Sandick JW, Maurits Swellengrebel HA, Lind PA, Putter H, Jansen EP, et al. Neoadjuvant chemotherapy followed by surgery and chemotherapy or by surgery and chemoradiotherapy for patients with resectable gastric cancer (CRITICS). BMC Cancer. 2011;11:329.

24. Kim MS, Lim JS, Hyung WJ, Lee YC, Rha SY, Keum KC, et al. Neoadjuvant chemoradiotherapy followed by D2 gastrectomy in locally advanced gastric cancer. World J Gastroenterol. 2015;21:27118.

\section{Tables}

Table 1. Baseline characteristics of 65 locally advanced/metastatic gastric cancer patients 


\begin{tabular}{|c|c|}
\hline \multirow{2}{*}{\multicolumn{2}{|c|}{ Age, years }} \\
\hline & \\
\hline Mean (range) & $65.4(31-85)$ \\
\hline$\geqq 65$ years & $33(50.8)$ \\
\hline $\begin{array}{l}<65 \text { years } \\
\text { Gender }\end{array}$ & $32(49.2)$ \\
\hline Male & $42(64.6)$ \\
\hline $\begin{array}{c}\text { Female } \\
\text { Tumor size }\end{array}$ & $23(35.4)$ \\
\hline$<5 \mathrm{~cm}$ & $36(55.4)$ \\
\hline Clinical T status & $29(44.6)$ \\
\hline $\mathrm{T} 4$ & 47 (72.3) \\
\hline $\begin{array}{l}\text { T3 } \\
\text { Clinical N status }\end{array}$ & $18(27.7)$ \\
\hline N1 & $10(15.4)$ \\
\hline $\begin{array}{l}\mathrm{N} 2+\mathrm{N} 3 \\
\text { Vascular invasion }\end{array}$ & $55(84.6)$ \\
\hline Positive & $10(15.4)$ \\
\hline Negative & $13(20.0)$ \\
\hline $\begin{array}{l}\text { ND } \\
\text { Perineural invasion }\end{array}$ & $42(64.6)$ \\
\hline Positive & $11(16.9)$ \\
\hline Negative & $12(18.5)$ \\
\hline $\begin{array}{l}\text { ND } \\
\text { Clinical TNM stage }\end{array}$ & $42(64.6)$ \\
\hline Stage III & $41(63.1)$ \\
\hline $\begin{array}{l}\text { Stage IV } \\
\text { Tumor location }\end{array}$ & $24(36.9)$ \\
\hline Cardiac & $18(27.7)$ \\
\hline Body & $18(27.7)$ \\
\hline Antrum & $31(47.7)$ \\
\hline Diffuse (Borrmann IV) & $18(27.7)$ \\
\hline $\begin{array}{l}\text { Stump } \\
\text { Histology }\end{array}$ & $3(4.6)$ \\
\hline
\end{tabular}




\begin{tabular}{|c|c|}
\hline Well-Differentiated & 0 \\
\hline Moderately Differentiated & $6(9.2)$ \\
\hline Poorly Differentiated & $19(29.2)$ \\
\hline $\begin{array}{l}\text { ND } \\
\text { Metastasis site }\end{array}$ & $40(61.5)$ \\
\hline Peritoneum carcinomatosis & $8(12.3)$ \\
\hline Liver & $7(10.8)$ \\
\hline Lung & $6(9.2)$ \\
\hline Bone & $2(3.1)$ \\
\hline Ovary & $3(4.6)$ \\
\hline $\begin{array}{l}\text { Bladder } \\
\text { Pre-treatment CEA (ng/ml) }\end{array}$ & $1(1.5)$ \\
\hline$\geqq 5$ & $16(24.6)$ \\
\hline$<5$ & $49(75.4)$ \\
\hline \multicolumn{2}{|l|}{ Post-treatment CEA (ng/ml) } \\
\hline$\geqq 5$ & $20(30.8)$ \\
\hline $\begin{array}{l}<5 \\
\text { TNM down-staging }\end{array}$ & $45(69.2)$ \\
\hline Yes & $18(27.7)$ \\
\hline $\begin{array}{l}\text { No } \\
\mathrm{T} \text { down-staging }\end{array}$ & $47(72.3)$ \\
\hline Yes & $17(26.2)$ \\
\hline $\begin{array}{l}\text { No } \\
\mathrm{N} \text { down-staging }\end{array}$ & $48(73.8)$ \\
\hline Yes & $16(24.6)$ \\
\hline $\begin{array}{l}\text { No } \\
\text { R0/R1 resection }\end{array}$ & $49(75.4)$ \\
\hline Yes & $25(38.5)$ \\
\hline $\begin{array}{l}\text { No } \\
\text { CCRT or Chemotherapy }\end{array}$ & $40(61.5)$ \\
\hline CCRT & $30(46.2)$ \\
\hline Chemotherapy & $35(53.8)$ \\
\hline
\end{tabular}

$\mathrm{ND}=$ Not done (38 patients: unresectable tumor; 2 patients: complete response after neoadjuvant chemoradiotherapy); CEA: carcinoembryonic antigen; CCRT=concurrent 
chemoradiotherapy

Table 2. Grade 3/4 toxicities according to the National Cancer Institute Common Terminology Criteria for Adverse Events

\begin{tabular}{lllll}
\hline & Total & CCRT & Chemotherapy & $P$-value \\
& $\mathrm{N}=65(\%)$ & $\mathrm{N}=30(\%)$ & $\mathrm{N}=35(\%)$ & \\
\hline lematologic & $8(12.3)$ & $3(10.0)$ & $5(14.3)$ & 1.000 \\
Neutropenia & $4(6.2)$ & $2(6.7)$ & $2(5.7)$ & 1.000 \\
Febrile neutropenia & $3(4.6)$ & $1(3.3)$ & $2(5.7)$ & 1.000 \\
Thrombocytopenia & $1(1.5)$ & 0 & $1(2.9)$ & 1.000 \\
lon-hematologic & $44(67.7)$ & $20(66.7)$ & $24(68.6)$ & 0.768 \\
Nausea/Vomiting & $10(15.4)$ & $5(16.7)$ & $5(14.3)$ & 1.000 \\
Anorexia/Fatigue & $9(13.8)$ & $4(13.3)$ & $5(14.3)$ & 0.708 \\
Abnormal liver function & $5(7.7)$ & $2(6.7)$ & $3(8.6)$ & 1.000 \\
Abnormal renal function & $5(7.7)$ & $2(6.7)$ & $3(8.6)$ & 1.000 \\
Peripheral neuropathy & $4(6.2)$ & $2(6.7)$ & $2(5.7)$ & 1.000 \\
Stomatitis & $4(6.2)$ & $3(10.0)$ & $1(2.9)$ & 0.270 \\
Diarrhea & $4(6.2)$ & $2(6.7)$ & $2(5.7)$ & 1.000 \\
Constipation & $3(4.6)$ & 0 & $3(8.6)$ & 0.255 \\
\hline
\end{tabular}

CCRT=concurrent chemoradiotherapy

Table 3. Correlation between CCRT or CT and clinicopathologic features in 65 locally advanced/metastatic gastric cancer patients 


\begin{tabular}{|c|c|c|c|c|}
\hline & $\begin{array}{l}\text { Total } \\
\mathrm{N}=65\end{array}$ & $\begin{array}{c}\text { CCRT } \\
\mathrm{N}=30(\%)\end{array}$ & $\begin{array}{c}\text { Chemotherapy } \\
\mathrm{N}=35(\%)\end{array}$ & $P$-value \\
\hline \multicolumn{5}{|l|}{ Age, years } \\
\hline$\geqq 65$ years & $33(50.8)$ & $10(33.3)$ & $23(65.7)$ & \multirow[t]{2}{*}{0.013} \\
\hline$<65$ years & $32(49.2)$ & $20(66.7)$ & $12(34.3)$ & \\
\hline \multicolumn{5}{|l|}{ Gender } \\
\hline Male & $42(64.6)$ & $22(73.3)$ & $20(57.1)$ & \multirow[t]{2}{*}{0.202} \\
\hline Female & $23(35.4)$ & $8(36.7)$ & $15(42.9)$ & \\
\hline \multicolumn{5}{|l|}{ Tumor size } \\
\hline$<5 \mathrm{~cm}$ & $36(55.4)$ & $13(43.3)$ & $23(65.7)$ & \multirow[t]{2}{*}{0.085} \\
\hline$\geqq 5 \mathrm{~cm}$ & $29(44.6)$ & $17(56.7)$ & $12(34.3)$ & \\
\hline \multicolumn{5}{|c|}{ Clinical T status } \\
\hline $\mathrm{T} 4$ & $47(72.3)$ & $21(70.0)$ & $26(74.3)$ & \multirow[t]{2}{*}{0.784} \\
\hline T3 & $18(27.7)$ & $9(30.0)$ & $9(25.7)$ & \\
\hline \multicolumn{5}{|c|}{ Clinical N status } \\
\hline N1 & $10(15.4)$ & 5 (16.7) & $5(14.3)$ & \multirow[t]{2}{*}{1.000} \\
\hline $\mathrm{N} 2+\mathrm{N} 3$ & $55(84.6)$ & $25(83.3)$ & $30(85.7)$ & \\
\hline \multicolumn{5}{|c|}{ Vascular invasion } \\
\hline Positive & $10(43.5)$ & $3(33.3)$ & $7(50.0)$ & \multirow[t]{2}{*}{0.680} \\
\hline Negative & $13(56.5)$ & $6(66.7)$ & $7(50.0)$ & \\
\hline \multicolumn{5}{|c|}{ Perineural invasion } \\
\hline Positive & $11(47.8)$ & $4(44.4)$ & $7(50.0)$ & \multirow[t]{2}{*}{1.000} \\
\hline Negative & $12(52.2)$ & $5(55.6)$ & $7(50.0)$ & \\
\hline \multicolumn{5}{|c|}{ Clinical TNM stage } \\
\hline Stage III & $41(63.1)$ & $20(66.7)$ & $21(60.0)$ & \multirow[t]{2}{*}{0.615} \\
\hline Stage IV & $24(36.9)$ & $10(33.3)$ & $14(40.0)$ & \\
\hline \multicolumn{5}{|c|}{ Pre-treatment CEA (ng/ml) } \\
\hline$\geqq 5$ & $16(24.6)$ & $4(13.3)$ & $12(34.3)$ & 0.082 \\
\hline
\end{tabular}




$\begin{array}{llll}<5 & 49(75.4) & 26(86.7) & 23(65.7)\end{array}$

Post-treatment CEA (ng/ml)
$\geqq 5$
$20(30.8) \quad 9(30.0)$
$11(31.4)$
1.000
$<5$
$45(69.2) \quad 21(70.0) \quad 24(68.6)$

Response rate
$\mathrm{CR}+\mathrm{PR}$
$18(27.7) \quad 10(33.3)$
$8(22.9)$
0.411
$\mathrm{SD}+\mathrm{PD}$
$47(72.3) \quad 20(66.7)$
$27(77.1)$

Disease control rate
$\mathrm{CR}+\mathrm{PR}+\mathrm{SD}$
$48(73.9) \quad 25(83.3)$
$23(65.7)$
0.158
$\mathrm{PD}$
$17(26.1) \quad 5(16.7)$
$12(34.2)$

R0/R1 Resection

\begin{tabular}{lllll} 
Yes & $25(35.5)$ & $11(36.7)$ & $14(40.0)$ & 0.804 \\
No & $40(61.5)$ & $19(63.3)$ & $21(60.0)$ & \\
\hline
\end{tabular}

CCRT: concurrent chemoradiotherapy; CEA: carcinoembryonic antigen; $\mathrm{CR}=$ complete response; $\mathrm{PR}=$ partial response; $\mathrm{SD}=$ stable disease; $\mathrm{PD}=$ progressive disease

Table 4. Univariate and multivariate analysis of predictors of response status in 65 locally advanced/metastatic gastric cancer patients 


\begin{tabular}{|c|c|c|c|c|c|}
\hline \multirow[b]{2}{*}{ Jariables } & \multirow{2}{*}{$\begin{array}{l}\text { Response } \\
(\mathrm{n}=18)(\%)\end{array}$} & \multirow{2}{*}{$\begin{array}{l}\text { Non-response } \\
(\mathrm{n}=47)(\%)\end{array}$} & \multirow{2}{*}{$\begin{array}{l}\text { Univariate } \\
p \text {-value }\end{array}$} & \multicolumn{2}{|c|}{$\begin{array}{c}\text { Multivariate } \\
\text { analysis }\end{array}$} \\
\hline & & & & $\begin{array}{l}\text { Odds } \\
\text { ratio }(95 \% \\
\text { CI) }\end{array}$ & $\begin{array}{l}P \text { - } \\
\text { value }\end{array}$ \\
\hline $\begin{array}{l}\text { tge, years (<65 years } \\
' \geqq 65)\end{array}$ & $\begin{array}{l}10(55.6) / 8 \\
(44.4)\end{array}$ & $\begin{array}{l}22(46.8) / 25 \\
(53.2)\end{array}$ & 0.587 & $\begin{array}{l}0.704(0.236- \\
2.098)\end{array}$ & 0.551 \\
\hline Jender (male/female) & $\begin{array}{l}12(66.7) / 6 \\
(33.3)\end{array}$ & $\begin{array}{l}30(63.8) / 17 \\
(36.2)\end{array}$ & 1.000 & $\begin{array}{l}1.133 \\
(0.360- \\
3.567)\end{array}$ & 0.869 \\
\hline $\begin{array}{l}\text { Гumor size }(<5 / \geqq 5 \\
\text { sm) }\end{array}$ & $\begin{array}{l}10(55.6) / 8 \\
(44.4)\end{array}$ & $\begin{array}{l}26(55.3) / 21 \\
(44.7)\end{array}$ & 1.000 & $\begin{array}{l}0.990 \\
(0.332- \\
2.955)\end{array}$ & 0.871 \\
\hline $\begin{array}{l}\text { Jlinical T status } \\
\text { (T3/T4) }\end{array}$ & $\begin{array}{l}8(44.4) / 10 \\
(55.6)\end{array}$ & $\begin{array}{l}10(21.3) / 37 \\
(78.7)\end{array}$ & 0.073 & $\begin{array}{l}0.338 \\
(0.106- \\
1.081)\end{array}$ & 0.101 \\
\hline $\begin{array}{l}\text { Jlinical N status } \\
\mathrm{N} 1 / \mathrm{N} 2+\mathrm{N} 3)\end{array}$ & $\begin{array}{l}5(27.8) / 13 \\
(72.2)\end{array}$ & $\begin{array}{l}5(10.6) / 42 \\
(89.4)\end{array}$ & 0.124 & $\begin{array}{l}0.310 \\
(0.077- \\
1.239)\end{array}$ & 0.202 \\
\hline $\begin{array}{l}\text { Jascular invasion } \\
\text { 'negative / positive } \\
\text { 'miss) }\end{array}$ & $\begin{array}{l}5(27.8) / 4 \\
(22.2) / 9(50.0)\end{array}$ & 8()$/ 6() / 33()$ & 1.000 & $\begin{array}{l}1.067 \\
(0.197- \\
5.769)\end{array}$ & 1.000 \\
\hline $\begin{array}{l}\text { ?erineural invasion } \\
\text { (negative / positive } \\
\text { 'miss) }\end{array}$ & $\begin{array}{l}5(27.8) / 4 \\
(22.2) / 9(50.0)\end{array}$ & $\begin{array}{l}7(14.9) / 7 \\
(14.9) / 33 \\
(70.2)\end{array}$ & 1.000 & $\begin{array}{l}0.800 \\
(0.149- \\
4.297)\end{array}$ & 1.000 \\
\hline $\begin{array}{l}\text { Jlinical TNM stage } \\
\text { (III/IV) }\end{array}$ & $\begin{array}{l}11(61.1) / 7 \\
(38.9)\end{array}$ & $\begin{array}{l}30(63.8) / 17 \\
(36.2)\end{array}$ & 1.000 & $\begin{array}{l}1.123 \\
(0.367- \\
3.438)\end{array}$ & 0.779 \\
\hline $\begin{array}{l}\text { ?re-treatment CEA } \\
<5 / \geqq 5)(\mathrm{ng} / \mathrm{ml})\end{array}$ & $\begin{array}{l}14(77.8) / 4 \\
(22.2)\end{array}$ & $\begin{array}{l}35(74.5) / 12 \\
(25.5)\end{array}$ & 1.000 & $\begin{array}{l}0.833 \\
(0.229- \\
3.028)\end{array}$ & 1.000 \\
\hline $\begin{array}{l}\text { ?ost-treatment CEA } \\
<5 / \geqq 5)(\mathrm{ng} / \mathrm{ml})\end{array}$ & $\begin{array}{l}15 \\
(83.3) / 3(16.7)\end{array}$ & $\begin{array}{l}30(63.8) / 17 \\
(36.2)\end{array}$ & 0.148 & $\begin{array}{l}0.353 \\
(0.089- \\
1.396)\end{array}$ & 0.286 \\
\hline ¿CRT/Chemotherapy & $\begin{array}{l}10(55.6) / 8 \\
(44.4)\end{array}$ & 20()$/ 27()$ & 0.411 & $\begin{array}{l}1.688 \\
(0.565- \\
5.043)\end{array}$ & 0.511 \\
\hline JCR (yes/no) & $18(100.0) / 0$ & $\begin{array}{l}30(63.8) / 17 \\
(36.2)\end{array}$ & 0.003 & 1.600 & 0.002 \\
\hline
\end{tabular}


30/R1 resection

yes/no)
$11(61.1) / 7$

(38.9)
$14(29.8) / 33$ $(70.2)$
0.026

3.704

$(1.190-$

11.527)

CEA: carcinoembryonic antigen; $\mathrm{CCRT}=$ concurrent chemoradiotherapy

\section{Figures}

\section{Figure 1}

Cumulative overall survival rates of the 65 enrolled patients with unresectable locally advanced or metastatic gastric cancer undergoing preoperative neoadjuvant concurrent chemoradiotherapy or chemotherapy, as assessed using the Kaplan-Meier method. The differences in survival rates were analyzed using the log-rank test.

\section{Figure 2}

Cumulative progression-free survival rates of the 65 enrolled patients with unresectable locally advanced or metastatic gastric cancer undergoing preoperative neoadjuvant concurrent chemoradiotherapy or chemotherapy, as assessed using the Kaplan-Meier method. The differences in survival rates were analyzed using the log-rank test. 